Faculty. Soon after, he visited Moscow to see the genetical researches of Chetverikov and his group, who had stocks of Drosophila given to them by H.J. Muller. Then he migrated to Leningrad, and was sent on scientific expeditions to Central Asia to study genetic variation in domestic animals - he seems to have studied nearly every other biological phenomenon as well, especially human beings. The first part of this book is his enthralling reminiscences of his travels in Central Asia between 1925 and 1927 . In 1927 he and his wife went to the USA to work with Thomas Hunt Morgan at Columbia University, and he began that illustrious career in population genetics using Drosophila.

The problems arising from his investigations into populations of Drosophila in the USA demanded wider genetical explorations. The letters in the book (unfortunately we are never told to whom they were written, which would often clarify their mode of treatment of some topics) were written on his visits to Brazil (1948-1953), to other countries of South America (1955-1958), to Israel, Lebanon and Egypt (1956) and India, Indonesia and New Guinea (1960). He must have been a superb correspondent. As is to be expected, since the reminiscences were taped later in his life and the first letter dates from 1948, his character, after the sometimes hair-raising experiences of his youth, was fully formed. Thus we see no development of character in the book any more than there is in, for example, the short stories of "Saki", but the absence of that is more than compensated for by being able to see through the eyes of so good an observer and writer such a variety of landscapes, organisms, people and situations, sometimes hilarious, often exasperating, but always exciting.

He had a naturalist's eye for animals, plants and people, and excellent appreciation of landscape (less so for geology), a sharpness for human (as well as animal) character, and a lovely dry humour, very like "Saki's", all of which come out just as well in his letters as they did in his conversation. No empty pomposity ever imposed on him, and not many other involuntary psychological deceptions. The freshness of his response to tropical nature seems at first naive (but never boring, gushing or silly) because it is so immediate, but naive he was not. $\mathrm{He}$ turned a sharp eye inwards on himself as well - there are some extremely interesting obiter dicta on his own reactions to mountains, uninhabited tropical islands, palms, the tropical night and the Holy Land.

Dedicated drosophilists must be warned that there is little in the book about Drosophila. Everyone else will find a lot in it.

A.J. Cain is Derby Professor of Zoology at the University of Liverpool.

\section{Missing the essential Professor Eysenck}

\section{P.E. Bryant}

Hans Eysenck: The Man and His Work. By H.B. Gibson. Pp.275. ISBN 0-7206-0566-0. (Peter Owen, London/Humanities Press, New Jersey: 1981.) £11.95, \$26.

THE mainspring of the considerable body of research carried out by Professor Eysenck and his colleagues has always been his theory of personality. This is based on two ideas: the first is that everyone's personality can be described in terms of the person's position along three separate dimensions, and the second that the mechanisms which underlie these dimensions are, in principle, discoverable.

None of the specific details of his account of personality - the use of factor analysis, the three dimensions of introversion-extraversion, neuroticism and psychoticism or the use of the notions of excitation and inhibition and, later, of arousal to explain these dimensions - was in itself particularly new, but it has led to a great deal of original and fruitful research and it has also propelled Eysenck into a series of major controversies.

Anyone who has spent half-an-hour or more with one of his many books will know something of the theory and will also have learned that Eysenck not only revels in these controversies but also writes about them vividly and lucidly. Such characterlogist. Controversy is the life-blood of psychology. The subject is still finding its feet, and this means that nothing much is certain and nothing can be taken for granted. Every single claim has to be argued over.

No one has recognized this or demonstrated it more than Eysenck. He is nettled, and often quite rightly, by anything that looks like a respectable consensus. It has been the established academic view that individual differences are rather unimportant in psychology, that people with extreme left-wing views are very different in personality from people on the extreme right, that psychoanalysis works, that a person's intellectual abilities are largely determined by the environment in which he grew up, that astrology is bunk and that smoking is a cause of cancer. Eysenck has at various times disagreed quite violently with all these respectable sentiments, and whether or not his objections are right they are always argued cogently.

His relish for battle and the clarity with which he presents his blow by blow accounts of them to psychologists and laymen alike represent an important contribution to psychology, but there is much more besides. He, more than anyone, shaped the development of clinical psychology in this country. He, too, fought valiantly and successfully against the unfortunate tendency among psychologists to istics are a distinct advantage in a psycho- break up into quite separate camps which do not talk to each other and which pursue different questions with quite different methods. Eysenck insisted that the question of personality was too important to be left just to the personality testers. The methods of experimental psychology, he argued, were also needed to explain why people are different from each other. $\mathrm{He}$ managed to build a bridge between the two camps which has lasted extraordinarily well, so that nowadays no one using personality questionnaires can afford to
Hans Eysenck - "nettled . . by anything that looks like a respectable consensus".

ignore laboratory research just as no one doing laboratory experiments can resort to the easy assumption that what is true about the behaviour of one person is true as well of everybody else. This link between two hitherto separate disciplines is in my view Eysenck's greatest achievement.

Such a man obviously deserves the accolade of a biography, and H.B. Gibson's account of Eysenck's life coming out as it does near to his retirement ought to give us a good idea not only of Eysenck's own development but also of his considerable influence on psychology over the last three decades. But it does not. Gibson's book is at its strongest when it recounts the simple facts about Eysenck's life - his early upbringing in the Weimar Republic and then under the Nazi regime, his revulsion against the Fascist system and his consequent move to England, his decision faute de mieux to study psychology (mieux in this case being physics), his early work with Burt and then his subsequent move under the tutelage of Aubrey Lewis to the Institute of Psychiatry in order to set up the clinical psychology department there.

But we need to know more than that and 
in particular we ought to be told in some detail about the controversies that have taken up so much of Eysenck's academic life, and also about the kind of man he is. On both these counts Gibson's book is a clear failure. He hardly deals with the controversies at all. Eysenck's own views are described reasonably well but the arguments about them, though sometimes mentioned, are never pursued, and again and again Gibson resorts to the excuse that the issues are too complex for his book. This is indeed an unfortunate contrast with the subject of his book who has never hesitated to introduce the layman to exactly the issues which Gibson so consistently avoids.

Thus one of the most obvious opportunities of a book like this - the chance to see how psychology has advanced with the help of lively debates seen through the life of one of its main controversialists - is almost totally lost. Worse still, at times the book's account of Eysenck's controversies is quite seriously misleading. For example, there is a chapter called the "Psychology of Politics" which deals with two very disparate topics. One is Eysenck's theory, published in the $1950 \mathrm{~s}$, of the personality types associated with various political views, and in particular his amusing claim that right- and left-wing extremists have much in common, a suggestion which did not endear him either to the left or to the right. The second is the debate about the question of the relative effects of heredity and environment which Eysenck formed so vigorously in the 1970s. As far as I can see, Gibson's only reason for putting these two issues together is his idea that one of the reasons for the violent hostility which greeted Eysenck's views about the importance of heredity was the vindictive rage felt by left-wing elements at the earlier suggestion that they were brothers under the skin of the Fascist foes. There may have been people as lunatic as this, but there were also some serious, well-argued objections which we are not given. We hear about the riots and the punches, but not about the debate.

Nor is the book much more helpful about Eysenck's own personality. It seems that over the years he fell out with many of his important colleagues, but the reasons why remain obscure. Eysenck is apparently shy: yet he has the habit of making outrageously immodest, public claims about his own abilities. Gibson has no explanation for this seeming paradox. Another issue which is left quite unsettled concerns Eysenck's attitude to other people. Gibson takes pains to show how kind Eysenck can be, and of ten the book adopts the style of a life of one of the saints as it ramblingly recounts this or that good deed by the professor. St Francis gave his cloak to a poor man: Eysenck took a whole day off to fetch a colleague's baby from hospital. But the book also relays some ungenerous comments made by Eysenck about and sometimes directly to other people. I simply do not know what to conclude, and yet the question is important because one of the major reasons for Eysenck's success has been his ability to keep a large number of people around him working with enthusiasm on his ideas. I should have liked to have known how he did it.

Gibson's book is interesting and often entertaining. But it gives us nothing like a proper assessment of Eysenck's formidable contribution to psychology over the past three decades.

P.E. Bryant is Watts Professor of Psychology at the University of Oxford.

\section{Archaeology in retrospect and in prospect}

\section{J. Desmond Clark}

$\overline{\text { A Short History of Archaeology. By Glyn }}$ Daniel. Pp.232. ISBN 0-500-05041-4. (Thames and Hudson: 1981.) £9.50, \$17.95. Antiquity and Man: Essays in Honour of Glyn Daniel. Edited by John D. Evans, Barry Cunliffe and Colin Renfrew. Pp.256. ISBN 0-500-05040-6. (Thames and Hudson: 1981.) £25.

IT IS probably true to say that no school of archaeology has done more in the decades immediately preceding and following the Second World War than has that at the University of Cambridge. There are the unique contributions of Grahame Clark to understanding Mesolithic and Neolithic economy; of Charles McBurney to Palaeolithic studies through his excavations in North Africa, Iran, Afghanistan and Britain; of David Clarke in revolutionizing theory and concepts in archaeology; and of Glyn Daniel through his special interest in and encyclopaedic knowledge of the history of archaeology and the study of megalithic monuments.

These were scholars unsurpassed in their fields and their experience, knowledge and teaching have been responsible for the training of an unrivalled nucleus of the leading archaeologists working in the Western world today. In part this stems from the alliance between archaeology and anthropology that has always been present at Cambridge and the success of archaeological interpretation and model building has come from the understanding of human behaviour provided by ethnographic studies, not infrequently now being undertaken by the archaeologists themselves. While archaeology derives much of its methodology from the natural and earth sciences, interpretation can only come from the insights of the anthropologist. When Professor Glyn Daniel retired this July after 8 years in the Disney Chair at Cambridge and 35 years on the faculty, an era in British archaeology drew to a close. A new group of scholars, often his own students, have taken up the challenge of the modern, conceptual approach to the discipline and are among the leading contributors to it.

There is no one who has made more of an impact than Professor Daniel on our understanding of the history of archaeology and the way that this has influenced current theory, and on the story of its emer- gence from the enveloping strait-jacket of the Book of Genesis to become the creative and exciting discipline it is today. To celebrate his general editorship and the appearance of the hundred th volume in the Ancient Peoples and Places series published by Thames and Hudson, he has produced $A$ Short History of Archaeology.

The volume is divided into five main chapters that cover the growth of archaeological method and theory from the beginnings, through the formative and then the developmental years between the wars, to that of the "new and not-so-new archaeology". This is a well-written, witty and enjoyable summary of the main conceptual, analytical and methodological advances in the field of prehistoric and historic archaeology as manifested by accounts of the increasing numbers of significant and often very exciting finds, the development of survey, excavation and recording techniques, and the awakening interest of the general public. In other words, it is an excellent history of mankind's ideas about his ancient past. This approach enables archaeologists to appreciate the value of the historical framework that has made possible the advances in field work, analysis and interpretation of the past two decades. By trying to understand the tenor of intellectual thought at a particular time we are better able to appreciate the major developments in archaeological theory and the reasoning that lies behind them.

Following the ordering of assemblages of artefacts in the Three Ages System, to that of the Stage or Age based on stratigraphic excavation and the concept of the "type fossil", archaeology has moved on to determining patterns of economic and social behaviour. The major concern with chronology and time-depth, which for so long occupied the earlier archaeologists, has only been removed since the availability of techniques such as radiocarbon, potassium-argon and the palaeomagnetic reversal chronology made possible by physicists, chemists and geologists since 1950. We are now, therefore, in a position to know, even if we cannot comprehend, the magnitude of the time involved in the story of our biological and cultural evolution.

A Short History of Archaeology is a synthesis not only of the record for 